J Arid Land (2015) 7(3): 403-413

doi: $10.1007 / \mathrm{s} 40333-014-0039-\mathrm{Z}$

jal.xjegi.com; www.springer.com/40333

\title{
Species-specific traits determine shrub-annual interactions during a growing season
}

\author{
GeFei ZHANG, WenZhi ZHAO* \\ Linze Inland River Basin Research Station, Key Laboratory of Ecohydrology of Inland River Basin, Cold and Arid Regions Environmental \\ and Engineering Research Institute, Chinese Academy of Sciences, Lanzhou 730000, China
}

\begin{abstract}
Stress gradient hypothesis predicted that facilitative interactions usually increase in intensity and are importance with abiotic stress. By contrast, facilitation may be lost in time, when it involves the growth of benefactors or beneficiaries. Less is known about which response pattern is more common in arid desert. We present an empirical study to explore shrub-annual interactions at the community and individual level along the course of a single growing season in a desert steppe in northwest China. Here the severity of drought stress may increase in time due to uneven precipitation during plant growing season. We assessed growth responses of annuals in understory where two dominant shrubs were removed. Annuals responses showed a switch from weakly positive to more strongly positive beneath Calligonum mongolicum, whereas from positive to negative beneath Nitraria sphaerocarpa during the growing season. Additionally, annual species with contrasting functional traits showed distinct growth responses to canopies removal. There was evidence of an increase in soil moisture below the canopy of shrubs, but a decrease in potential evaporation rate and photosynthetically active radiation, which can partly explain these species-specific responses. We conclude that the balance between competitive and facilitative effects in shrub-annual interactions is not only governed by the severity of stress but also determined by plant traits, such as canopy structure of shrubs and functional traits of their understory annuals.
\end{abstract}

Keywords: competition; facilitation; functional trait; stress gradient; temporal variation

Citation: GeFei ZHANG, WenZhi ZHAO. 2015. Species-specific traits determine shrub-annual interactions during a growing season. Journal of Arid Land, 7(3): 403-413. doi: 10.1007/s40333-014-0039-z

Previously, most researchers devoted to the study of negative interactions, such as competition, interference and predation, which have long been considered as the major processes structuring plant communities. A large number of recent empirical and theoretical studies have indicated that plants could sometimes benefit from near neighbors, especially in stressful environments like deserts, arctic or alpine tundra systems or salt marches (Choler et al., 2001; Bertness and Ewanchuk, 2002; Maestre and Cortina, 2004; Chu et al., 2009; Kikvidze and Callaway, 2009; He et al., 2012). Under harsh conditions, facilitative effects may play an essential role in plant survival, growth and reproduction (Callaway et al., 2002; Cavieres et al., 2006), and have important implications for species coexistence and community diversity (Bruno et al., 2003; Brooker et al., 2008).

In arid and semi-arid ecosystem, interactions between shrubs and understory species have been frequently reported (Callaway, 2007; Brooker et al., 2008). Desert shrubs have positive effects on the growth and fecundity of understory species due to higher nutrient availability (Kidron and Gutschick, 2013), micro-climatic amelioration (Callaway, 1995), offering protection from herbivores (Veblen, 2008) and against windblown sand (Zhao et al., 2008). It was proposed that water can play an important role in regulating shrub-annual interactions in arid lands. With the capacity for moisture retaining or hydraulic lifting, shrubs can provide water to neighbors with

*Corresponding author: WenZhi ZHAO (E-mail: zhaowzh@1zb.ac.cn; zhanggf@1zb.ac.cn)

Received 2014-05-16; revised 2014-07-25; accepted 2014-08-13

(C) Xinjiang Institute of Ecology and Geography, Chinese Academy of Sciences, Science Press and Springer-Verlag Berlin Heidelberg 2015 
shallow roots (Maestre et al., 2003; Ludwig et al., 2004). Sometimes, canopy shade indirectly facilitates neighbors by decreasing plant transpiration rate without a substantial cost to itself (Maestre et al., 2008). Yet, competition is also intense in arid and semi-arid environments (Maestre et al., 2008), which usually occur even when the net outcome of a plant-plant interaction is facilitation.

The net plant-plant interactions are suggested to be most related to the type and intensity of environmental severity or the ontogeny progress of interacting species (Armas and Pugnaire, 2005; Weedon and Facelli, 2008). As predicted by stress gradient hypothesis (SGH), facilitative interactions usually increase in intensity under stressful environments, whereas negative interactions prevail under benign conditions (Michalet, 2006; Valladares and Niinemets, 2008; Maestre et al., 2009; Roux and McGeoch, 2010). A rather larger body of empirical data across a variety species and ecosystems support this prediction (Callaway, 2007; Maestre et al., 2008; He and Bertness, 2014). In addition to spatial or temporal variations in environmental stresses, balances between competition and facilitation also change in response to the growth of benefactors or beneficiaries. Miriti (2006) and Sthultz et al. (2007) proposed that the presence of mature shrubs could improve the demographic performance of juvenile beneficiaries, but diminishes the positive effect during the beneficiaries' growth (also see Callaway, 2007). Similarly, the transition of benefactors from "young" to "old" stage can also switch net plant-plant interactions from facilitation to competition (Reisman-Berman, 2007).

Hexi desert region located in the southwest of Badain Jaran Desert, is one of the areas of most serious concern for land desertification in China. The environment is dominated by a continental arid temperate climate. Here rainfall distribution is uneven, showing a shift from moist season to dry season during plant growth period. Obviously, environmental stress should increase along the course of a growing season, because water is the primary factor limiting plant growth and reproduction in this region. Thus, if the expectation of SGH is necessarily an increase in positive interactions in response to incremental abiotic stress, net plant-plant interactions may switch from negative to positive dur- ing a growing season. Yet, if the expectation is always an increase in competition but rather in facilitation with the growth of benefactor- or beneficiary-plants, then this can be met in net plant-plant interactions by a shift from positive to negative during a growing season, which is the opposite of the usual prediction from SGH. Both alternatives make sense in theory. Only empirical evidence will show which type of response is more common in plant-plant interactions during a growing season and whether this response varies among species in an arid ecosystem.

To address this empirical need, we investigated (i) the net effect of dominant desert shrubs on their understory plants along the course of a single growing season; and (ii) these effects differences among different shrub species or the understory annuals. We assessed plant-plant interactions at the community level by analyzing effects of canopy-neighbors on several co-occurring understory species in natural community. In order to assess mechanisms of plant-plant interactions, we also conducted several environmental measurements in shrub and removed-shrub micro-sites.

\section{Materials and methods}

\subsection{Study area}

The study area is located in the extreme southwest of Badain Jaran Desert, Linze county of Gansu province, China $\left(39^{\circ} 22^{\prime}-39^{\circ} 23^{\prime} \mathrm{N}, 100^{\circ} 07^{\prime}-100^{\circ} 08^{\prime} \mathrm{E}\right)$. The annual precipitation averages $116.8 \mathrm{~mm}$, while the potential evaporation is $2,390 \mathrm{~mm} / \mathrm{a}$. The growing season is generally from May to October. Monthly precipitation is highest in July, and then decreases significantly (Table 1; Fig. 1). The annual mean temperature is about $7.6^{\circ} \mathrm{C}$ with about 200 frost days; the lowest temperature is $-27.3^{\circ} \mathrm{C}$ in January, and the highest temperature is $39.1^{\circ} \mathrm{C}$ in July. Due to multiple stresses, such as extreme precipitation, nutrient and temperature, vegetation cover in the desert area only ranges from 5\% to 7\% (Zhao and Liu, 2010). Both Calligonum mongolicum and Nitraria sphaerocarpa are most common shrub species in the natural community. Other desert shrubs such as Haloxylon ammodendron, Elaeagnus angustifolia and Tamarix ramosissi$m a$ are also distributed widely. The common annual 
Table 1 Change of monthly precipitation $(\mathrm{mm})$ during the growing season (from May to October) in the study area

\begin{tabular}{cccccc}
\hline Year & May & June & July & August & September \\
\hline $1987-2012$ & $10.2 \pm 1.99^{\mathrm{a}}$ & $23.0 \pm 3.54^{\mathrm{ab}}$ & $30.0 \pm 4.65^{\mathrm{b}}$ & $17.1 \pm 3.13^{\mathrm{ab}}$ & $14.6 \pm 3.68^{\mathrm{a}}$ \\
2013 & 9.1 & 26.8 & 62.8 & 6.0 & 1.8 \\
\hline Note: Little case letters indicate significance between months at $P<0.05$ level.
\end{tabular}

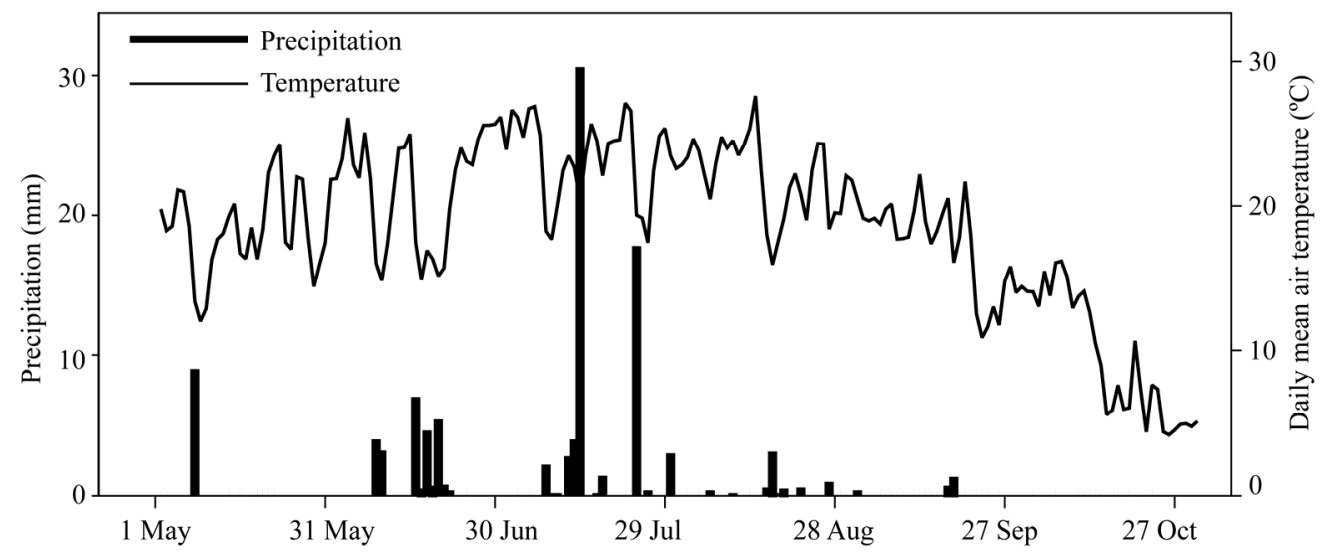

Fig. 1 Precipitation and daily mean air temperature in the study area from 1 May to 30 October

herbaceous species include Bassia dasyphylla, Corispermum lehmannianum, Salsola collina, Chloris virgata, Agriophyllum squarrosum and Halogeton arachnoideus.

\subsection{Experimental design and measurements}

To test the proposed issue, we carried out removal experiments during the growing season in summer 2013. Sampling was conducted in a community at semi-fixed dunes in which C. mongolicum and $N$. sphaerocarpa co-exist. The growing season of annual species from June to October was divided into two separate stages: an "early period" and a "late period".

(1) "Early period" At the beginning of growing season on 10 June 2013, fifteen pairs of C. mongolicum shrubs approximately $1-\mathrm{m}$ high and $1-1.5-\mathrm{m}$ diameter and other fifteen pairs of $N$. sphaerocarpa shrubs approximately $0.2-\mathrm{m}$ high and $1.5-2.5-\mathrm{m}$ diameter were selected and marked for the shrub removal treatment. Distance between paired shrubs ranged from 5 to $10 \mathrm{~m}$, to minimize environmental differences, but far apart enough to make sure that they cannot influence each other. After the selection of pairs, one randomly chosen shrub within each pair was removed at ground level. On 10 August, we placed one quadrat $(2 \mathrm{~m} \times 2 \mathrm{~m})$ beneath each shrub and other one quadrat in each removed-shrub site. All annuals in the quadrats were identified and counted for each species and then cut at ground level, oven-dried at $80^{\circ} \mathrm{C}$ for $48 \mathrm{~h}$ and weighted to estimate above-ground biomass.

(2) "Late period" On 1 August, seventeen pairs of C. mongolicum shrubs (approximately 1.2-m high and $1.3-1.9-\mathrm{m}$ diameter) and twenty pairs of $N$. sphaerocarpa shrubs (approximately $0.3-\mathrm{m}$ high and 1.7-2.8-m diameter) were selected and treated respectively. Sample sizes were calculated depending on the number of suitable shrubs in community. On 1 October, we identified and counted each species in the quadrats and harvested the above-ground biomass of understory annuals in control and experimental treatments. The operation method is consistent with the experiment of "early period".

To measure soil moisture, we collected soil cores (5-10-cm depth, 5-cm diameter) from the five selected pairs. The soil water content of these samples was determined gravimetrically (oven-dried for $48 \mathrm{~h}$ at $110^{\circ} \mathrm{C}$ ). To determine potential evaporation, we inserted glass tubes $(1.6 \mathrm{~cm} \times 15 \mathrm{~cm})$ into the ground. The rim of tubes was $3-\mathrm{cm}$ above the ground avoiding soil mixture. We filled the tubes with deionized water up 
to 3-cm below the rim and measured water lost using a rule after a week's placement. There is no precipitation in the process of measuring potential evaporation. In each plot, we measured photosynthetically active radiation (PAR) with Field Scout Light Meters (Spectrum, Technologies, Inc., US) from 11:00 am to 01:00 pm on clear days. The probe was placed northsouth across each plot and PAR was recorded at $10-\mathrm{cm}$ above the soil surface beneath shrubs and at removed-shrub plots. The ratio between these two measurements was taken as a proxy for the percentage of light transmission.

\subsection{Data analysis}

In order to quantify responses of understory annuals to shrub effects, we calculated the relative interaction intensity (RII; Armas et al., 2004) based on plant biomass for each species and plot, as follows: $R I I=\left(X_{p}-X_{a}\right) /\left(X_{p}+X_{a}\right)$, where $X_{p}$ and $X_{a}$ are biomass or density of the understory plants in presence and absence of shrubs, respectively. RII is symmetrical around zero (indicates no significant interaction), with positive values indicating facilitation and negative values indicating competition. By using RII, we can directly compare plant biomass among different sampling species. One-sample $t$-test was performed in order to assess whether RII in each pairs differed from zero. No significant difference $(P>0.05)$ indicates no effect of shrubs on annuals performance.

We used one-way ANOVA and paired t-test to assess shrub removal effect on annual performances (total biomass, species richness, density and coverage) and three-way ANOVA to test shrub removal impact on abiotic measurements (soil moisture, potential evaporation, and the percentage of PAR in understory), with removal treatment, shrub species and sampling period as fixed factors. Least significant difference (LSD) tests were performed to determine the significance of treatment means at $P<0.05$ with the Tukey's HSD test. Data were transformed for normality before ANOVA, when necessary. All statistical tests were performed using the program IBM SPSS Statistics v20.0 (IBM Corp, Somers, New York).

\section{Results}

\subsection{Shrub removal and annual response}

In early growing season, there was significant effect of $C$. mongolicum removal on total biomass and density of the understory annuals, but no effect on species richness and coverage (Fig. 2). The presence of $N$. sphaerocarpa significantly increased total biomass, density and coverage of plant community in the understory, but has no effect on species richness (Fig. 2). In lately growing season, however, C. mongolicum had a positive effect on their understory annuals, while $N$. sphaerocarpa showed a negative effect on annuals (Fig. 2). Plots under canopies of C. mongolicum had greater total biomass, density, richness and coverage than plots in bare soil. By contrast, the removal of $N$. sphaerocarpa remarkable increased plant biomass, density and coverage in lately growing season. During the growing season, net interactions between $C$. mongolicum and the understory plants showed a switch from weakly positive to more strongly positive, while from positive to negative interactions between $N$. sphaerocarpa and their understory plants (Fig. 3).

\subsection{Environmental factors}

Soil water content showed remarkable differences between shrub removed plots and canopy shading plots ( $F=68.247, P<0.001 ;$ Fig. 4). When a three-way ANOVA was performed, sampling period ( $F=49.497$, $P<0.001)$ and shrub species $(F=70.785, P<0.001)$ were found to influence soil moisture, with significant interaction between shrub species and removal treatments $(F=11.805, P=0.001)$.

The average of evaporation rates per day under both shrub canopies were significantly lower in comparison with open area $(F=51.764, P<0.001$; Table 2). Although potential evaporation showed significant differences in different sampling periods, no effect was found among shrub species (Table 3). Meanwhile, shrub removal treatment has no significant interaction between both sampling periods and shrub species (Table 3).

Transient PAR (10-cm above the soil surface) under canopies of $C$. mongolicum and $N$. sphaerocarpa were $507.3 \pm 287.19$ and $292.7 \pm 221.94 \mu \mathrm{mol} /\left(\mathrm{m}^{2} \cdot \mathrm{s}\right)$, and $1,679.6 \pm 131.36$ and $1,695.5 \pm 138.86 \mu \mathrm{mol} /\left(\mathrm{m}^{2} \cdot \mathrm{s}\right)$, respectively, in shrub removal plots. Shrub species and sam- 
pling period significantly affected the percentage of PAR transmission $(F=42.995, P<0.001$ and $F=33.841$, $P<0.001$, respectively), with the interaction of species and sampling period being significant $(F=5.977$, $P=0.015)$. Percentage of PAR transmission remark-
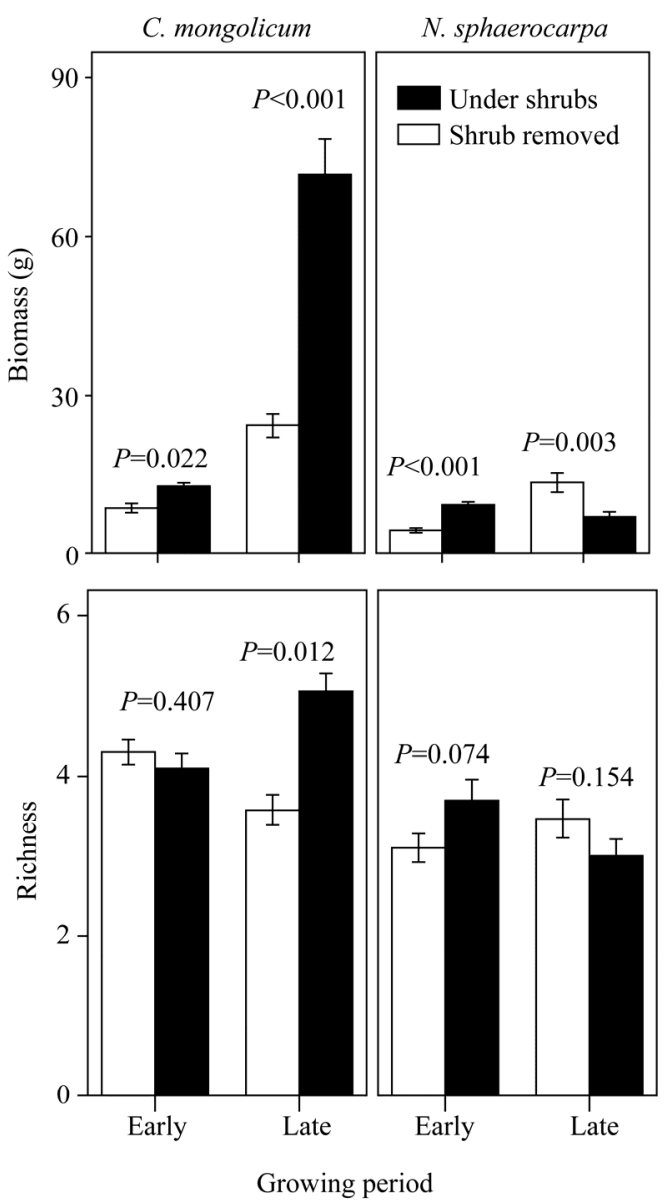

ably declined during growing season (Fig. 5), with transient PAR in understory varied from 562.9 \pm 327.17 to $451.6 \pm 230.81 \mu \mathrm{mol} /\left(\mathrm{m}^{2} \cdot \mathrm{s}\right)$ for $C$. mongolicum and from $426.5 \pm 193.52$ to $158.9 \pm 159.82 \mu \mathrm{mol} /\left(\mathrm{m}^{2} \cdot \mathrm{s}\right)$ for N. sphaerocarpa.
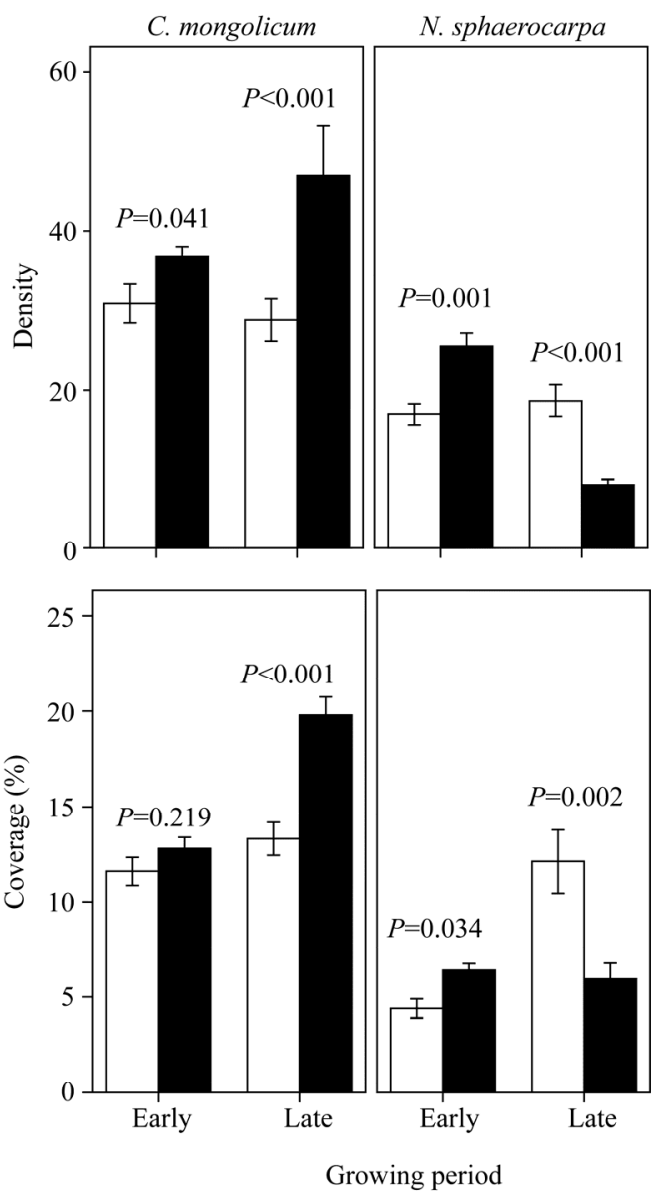

Fig. 2 Effects of shrub canopies of C. mongolicum and N. sphaerocarpa on total biomass, density, species richness and coverage in understory plots during the growing season. Effects of shrub canopies on performances of understory plants were analyzed with paired $\mathrm{t}$-test in each sampling period and shrub species. Data are means $\pm \mathrm{SE}$.

Table 2 Potential evaporation rate $(\mathrm{mm})$ with or without shrub canopies of $C$. mongolicum and N. sphaerocarpa

\begin{tabular}{|c|c|c|c|c|}
\hline \multirow{2}{*}{ Sampling period } & \multicolumn{2}{|c|}{ C. mongolicum } & \multicolumn{2}{|c|}{ N. Sphaerocarpa } \\
\hline & Shrub removed & Under shrubs & Shrub removed & Under shrubs \\
\hline 10 Jun-15 Jun (6 d) & $33.2 \pm 6.50$ & $28.4 \pm 4.33$ & $28.8 \pm 2.39$ & $25.0 \pm 4.00$ \\
\hline 1 Jul-8 Jul (8 d) & $41.8 \pm 12.50$ & $29.8 \pm 5.63$ & $46.0 \pm 10.61$ & $35.6 \pm 11.04$ \\
\hline $18 \mathrm{Jul}-24 \mathrm{Jul}(7 \mathrm{~d})$ & $52.2 \pm 11.52$ & $32.0 \pm 5.96$ & $42.0 \pm 8.90$ & $31.8 \pm 8.47$ \\
\hline 20 Aug-27 Aug (8 d) & $38.2 \pm 8.93$ & $29.0 \pm 3.67$ & $47.0 \pm 6.32$ & $31.2 \pm 7.05$ \\
\hline 3 Sep-10 Sep ( $8 d)$ & $50.0 \pm 14.71$ & $31.0 \pm 9.67$ & $41.4 \pm 16.1$ & $33.4 \pm 4.83$ \\
\hline 10 Sep-17 Sep ( $8 d)$ & $45.4 \pm 10.11$ & $30.0 \pm 9.75$ & $53.8 \pm 14.74$ & $38.4 \pm 6.80$ \\
\hline Average per day & $6.73 \pm 1.84^{\mathrm{a}}$ & $4.7 \pm 1.12^{\mathrm{b}}$ & $6.61 \pm 1.59^{\mathrm{a}}$ & $5.02 \pm 1.08^{\mathrm{b}}$ \\
\hline
\end{tabular}

Note: Sampling period shows dates of placement and measurement of glass tubes; letters show Tukey's HSD post hoc analysis between months with ANOVA; values not sharing a letter are significantly different at $P<0.05$ level. 

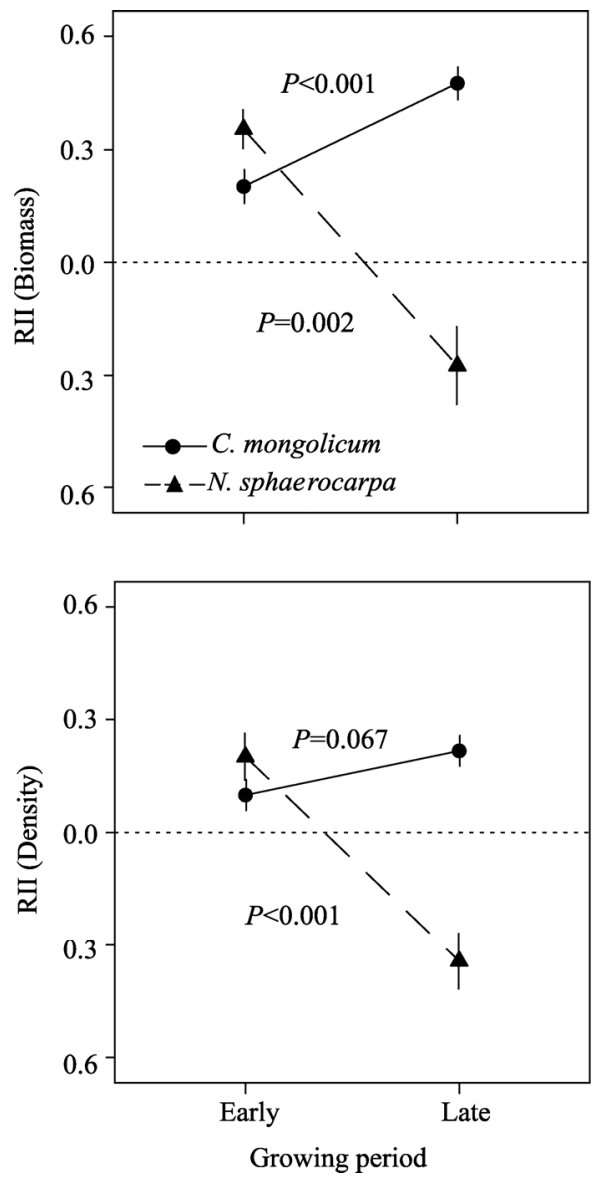

Fig. 3 Relative interaction intensity (RII) values for total biomass and plant density of the understory plots. RII values in different growing periods were analyzed with one-way ANOVA in both shrub species. Negative value represents a negative interaction between shrubs and their understory annuals, while positive value represents a positive interaction. Data are means $\pm S E$.

Table 3 Effect of canopy removed, sampling period and species on the potential evaporation (which is in $\mathrm{mm} / \mathrm{d}$ )

\begin{tabular}{lrrrc}
\hline Source & $\begin{array}{c}\text { Type III sum } \\
\text { of squares }\end{array}$ & $d f$ & $F$ & $P$ \\
\hline Period & 23.443 & 5 & 2.448 & $\mathbf{0 . 0 3 9}$ \\
Removal & 99.147 & 1 & 51.764 & $<\mathbf{0 . 0 0 1}$ \\
Species & 0.311 & 1 & 0.162 & 0.688 \\
Period $\times$ Removal & 8.181 & 5 & 0.854 & 0.515 \\
Period $\times$ Species & 20.305 & 5 & 2.120 & 0.069 \\
Removal $\times$ Species & 1.546 & 1 & 0.807 & 0.371 \\
Period $\times$ Removal $\times$ Species & 6.240 & 5 & 0.652 & 0.661 \\
Error & 183.875 & 96 & & \\
\hline
\end{tabular}

Note: $P$ values below 0.05 are in bold.

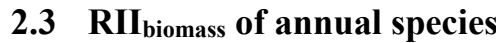

Both shrub species had positive effects on biomass

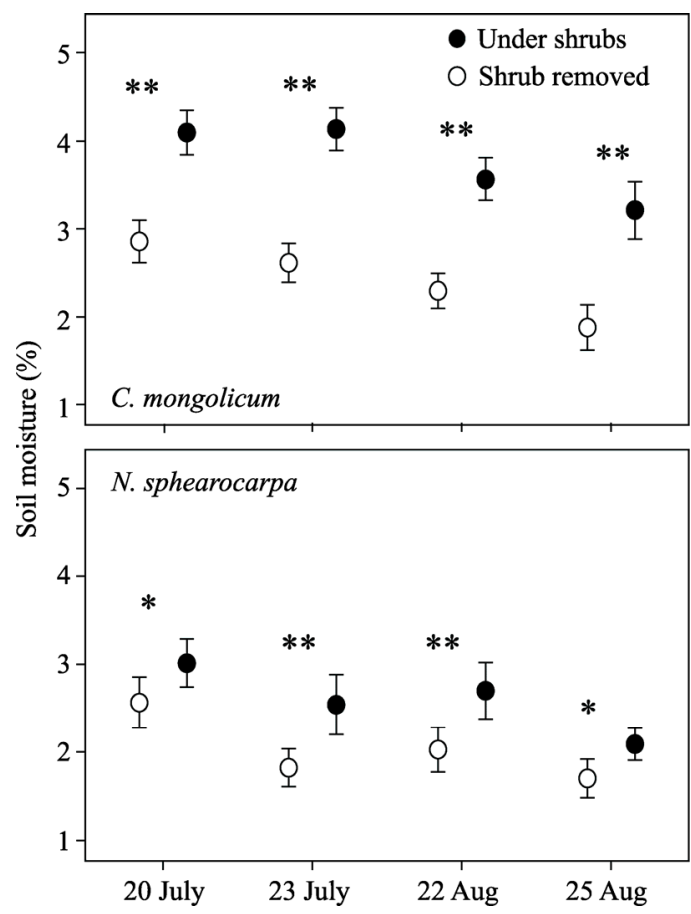

Fig. 4 Effects of shrub canopies of C. mongolicum and $N$. sphaerocarpa on soil moisture in understory. Effects of shrub removal on soil water content were analyzed with one-way ANOVA in each sampling period and shrub species; Data are means \pm SE. * and $* *$ indicate significance at $P<0.05$ and $P<0.01$, respectively.

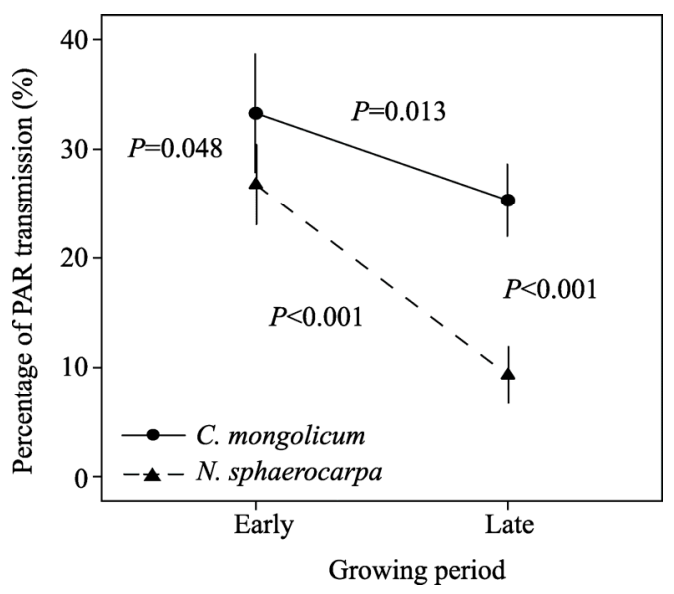

Fig. 5 Percentage of transient photosynt $\neg$ hetically active radiation (PAR) transmission (10-cm above soil surface) under $C$. mongolicum and $N$. sphaerocarpa among different growing periods. Effects of shrub canopies on PAR in understory were analyzed with one-way ANOVA in each sampling period and shrub species.

of B. dasyphylla and S. collina in early growing season (Figs. 6a and b). However, RII values of $B$. dasyphylla and $S$. collina showed differences between $C$. mongolicum and $N$. sphaerocarpa in lately growing season. For C. mongolicum, the magnitude of this ef- 
fect at late period was larger than early period (Fig. 6a; temporal variation in effect of $C$. mongolicum on $B$. dasyphylla is marginal significant, $P=0.052$ ). By con-
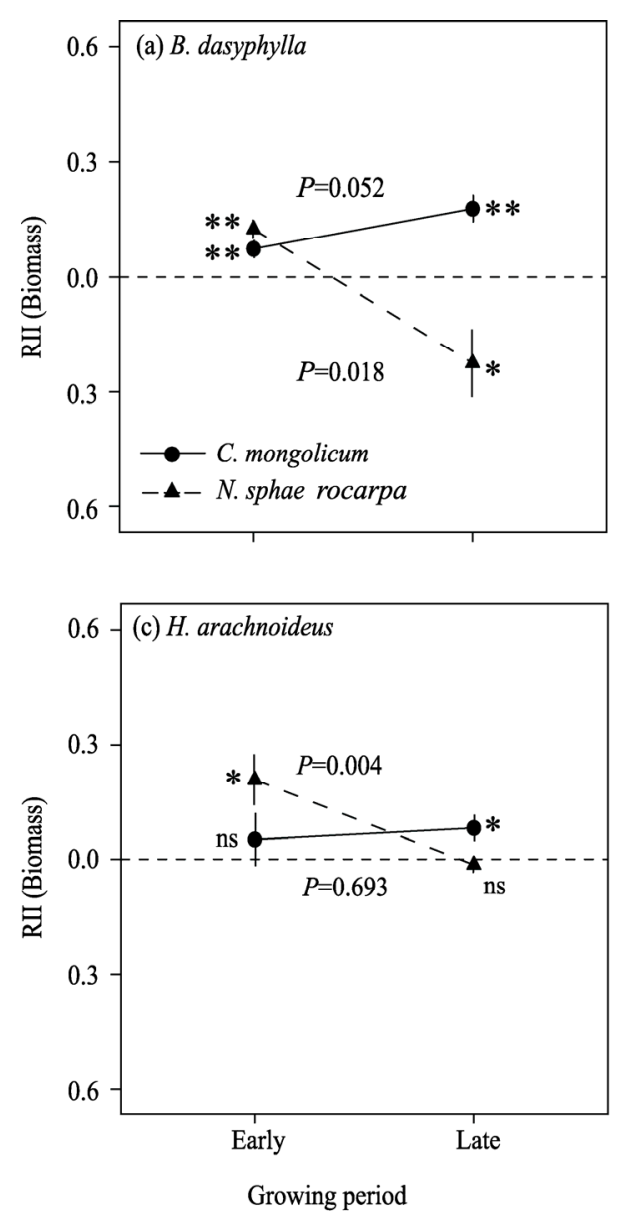

trast, for N. sphaerocarpa, the direction of shrub effect on both annuals significantly shifted from positive to negative during the growing season (Figs. 6a and $\mathrm{b}$ ).
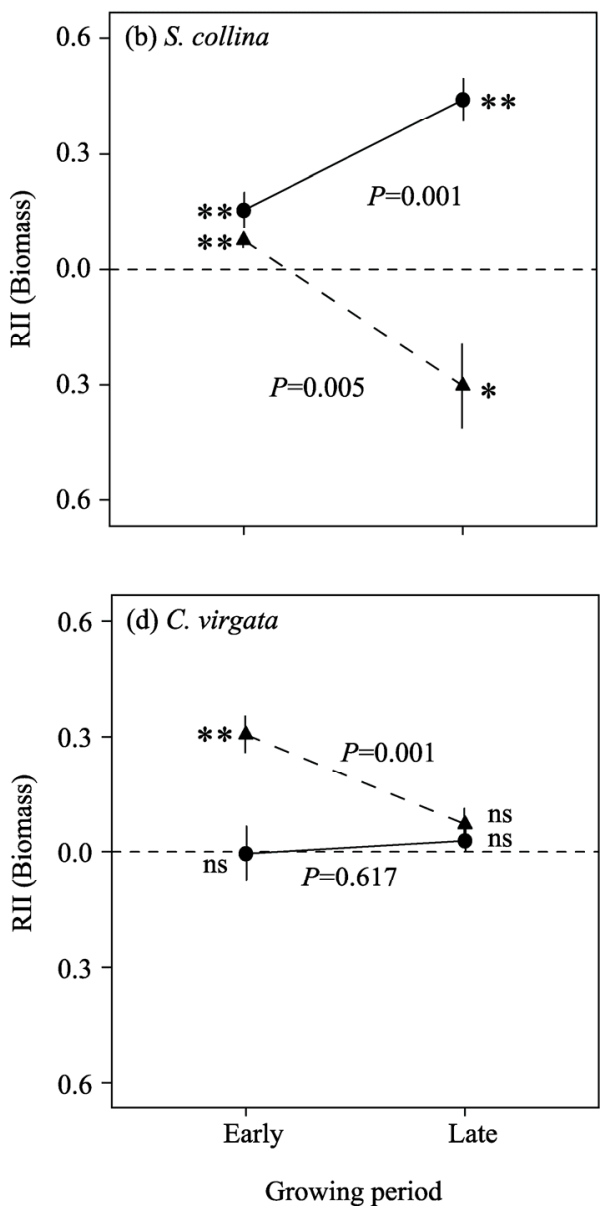

Fig. 6 RII values for biomass of B. dasyphylla (a) and S. collina (b) in understory, $H$. arachnoideus (c) and C. virgata (d). RII values in different growing periods were analyzed with one-way ANOVA; significances of RII were analyzed with one sample $t$-test; ** represents RII significantly different from 0 at $P<0.01$; represents significant at $P<0.05$; ns, not significant. Data are means \pm SE.

At early period, understory $H$. arachonideus and $C$. virgata have positive response to $N$. sphaerocarpa, while they had no significant response to $C$. mongolicum (Figs. 6c and d). The effect of $N$. sphaerocarpa on $H$. arachonideus and $C$. virgata showed a significant switch from positive to neutral. However, the direction and magnitude of this effect had not changed for annuls under C. mongolicum during the growing season, despite significant RII values of $H$. arachonideus at late period (Fig. 6c).

\section{Discussion and conclusion}

A main prediction of SGH is that positive interactions prevail under stressful environment due to habitat amelioration and associational defenses, whereas neg- ative interactions dominate under more benign conditions (Maestre et al., 2009). At the same time, it was also predicted that the role of facilitators weaken when beneficiaries mature or benefactors growth (Sthultz et al., 2007). However, little attention has been paid to exploring which prediction was more common in nature communities. In our study site, the nature gradient from moist to dry during the growing season makes the communities ideal for exploring this issue. Here, we found that shrub-annual interactions indeed changed according to intra-seasonal stress variations, but in a complicated manner that depended on species-specificity and sampling period.

\subsection{Temporal variation of interactions in a growing season}


Both C. mongolicum and N. sphaerocarpa positively affected the performances of their understory annuals in early growing season, similar to the well-known nurse plant effects (Callaway et al., 2005). The performances of annual species under shrub canopies are relatively more superior in comparison with open area. Interestingly, C. mongolicum and N. sphaerocarpa shrubs show completely opposite impacts on their understory annuals in lately growing season. Our results demonstrated that $C$. mongolicum positively affected the growth of their understory species, while $N$. sphaerocarpa negatively affected annual performances.

Many studies in arid and semi-arid ecosystems demonstrated a shift from competitive to facilitative in plant-plant interactions along an environmental stress gradient (He et al., 2011; Dohn et al., 2013). This response manifested not only in spatial scales (Kikvidze et al., 2011) but in temporal scales (Koyama and Tsuyuzaki, 2013; Bulleri et al., 2014). In the present study, C. mongolicum increases biomass, density and coverage of their understory annuals, while the magnitude of this positive effect is relatively larger in lately growing season. We assume that the observed response in annuals under the canopy of C. mongolicum is related to temporal variations in environmental stress. Although rainfall mainly happens during plant growing season, water is still the primary limited factor for plant survival and growth due to strong radiation and intense evaporation in this area. Furthermore, precipitation in late growing season is obviously lower in comparison with earlier period, indicating that plants will subject to more severe stress in late time of a year. These data agree with reports from other dry environments, showing a switch from competitive or neutral to facilitative due to aridity in the later year (Holzapfel and Mahall, 1999; Kikvidze et al., 2006). Yet there are several exceptions in arguments for alternatives to the SGH (He et al., 2013), as showed in our study that the response of annuals under canopies of $N$. sphaerocarpa.

As noted by Callaway (2007), shifting effects of shrubs from positive for establishment of other species to competitive for those species when they mature may be quite common and important in plant communities. Our results are consistent with current hypothesis that juveniles are more likely than adults to be beneficiaries of facilitation as they are more susceptible to environmental stress (Miriti, 2006). This can be partly proved by a higher plant density in early plots studied beneath shrub canopies, compared to bare soil. In late growing season, however, variations in necessary resources and increases of demand for growth space may cause an intensification of competition (Sthultz et al., 2007). Thus, the net interaction probably shifts from positive to negative with the growth of understory plants, which may be a possible explanation for the response of annuals under N. sphaerocar$p a$. However, this prediction cannot fully explain temporal variation in responses of annuals beneath co-existing C. mongolicum in the community. We hypothesize that this large discrepancy in annual responses under canopies of $C$. mongolicum and $N$. sphaerocarpa may be in part due to species-specific and growth related traits.

\subsection{Mechanisms underlying shrub-annual interact- ions}

The relatively high soil moisture under shrub canopies in our results was in agreement with previous studies reported from other arid and semi-arid region ( $\mathrm{Li}$ et al., 2010; Kidron and Gutschick, 2013). From our data, higher soil water content beneath shrubs can be explained by lower soil temperature and evaporation rates. Due to shade from direct sunbeams, potential evaporation rates on soil surface under shrubs were approximately $2 / 3^{\text {rd }}$ that of the adjacent canopy-removed sites. But in fact, the understory species can also influence soil moisture by changing evaporation and transpiration (water absorption) directly. Another potential explanation is that water-funneling effect of shrubs probably changes snowmelt recharge under canopies (Mauchamp and Janeau, 1993). Under the influence of snowmelt recharge during early spring, soil moisture beneath canopies of $\mathrm{H}$. ammodendron (another common desert shrub in northwestern China) was relatively higher in comparison with gaps (Li et al., 2010). In addition, many previous studies reported that woody perennials, such as trees and shrubs, might extract water from deep soil and lose it into dry soils at the surface, which will improve the water relations of their understory plants (Armas et al., 2012). However, there was no indication in any case of C. mongolicum and N. sphaerocarpa of the 
involvement of hydraulic lift up to now.

Canopy shading has multiple effects that can facilitate and impair their understory plants simultaneously. Mature shrubs usually reduce thermal amplitudes and decrease soil water evaporation, which facilitate germination of seeds and growth of seedlings (Callaway, 1995), and protect adult plant from fatal photo-inhibition (Moro et al., 1997). However, light interception by neighbors also limits photosynthetic activity of grasses, which in turn may lead to species loss (Hautier et al., 2009). Our results show that percentage of PAR in understory beneath $N$. sphaerocarpa is remarkably lower than under C. mongolicum. Meanwhile, the transient PAR transmission declines as the growth of canopies during a growing season. As suggested by Schramm and Ehrenfeld (2010), deep shading will unavoidably impact establishment, growth and reproduction of the understory plants. A recent study (Holmgren et al., 2012) also demonstrated this. Therefore we assume that the negative impact related to decreases in available lights may be stronger under $N$. sphaerocarpa than under C. mongolicum, and stronger in late than in early period during the growing season.

\subsection{Species-specificity affects shrub-annual inte- ractions}

As predicted by our hypothesis, changes in net shrubannual interactions may be due in part to temporal variation in growth-related traits. The direction and magnitude of net interactions was reported to be closely related to the ontogeny of beneficiaries (Miriti, 2006; Sthultz et al., 2007; Armas and Pugnaire, 2009). Meanwhile, it was proposed that the growth process of benefactors would also determine the interplay between facilitation and interference in time (Reisman-Berman, 2007). These previous studies have focused on impacts of temporal variation in age- or size-related traits on plant-plant interactions. Complementary to them, our results demonstrated that negative effects due to light interception might change according to canopy density in different species and periods. Variations in canopy traits not only take place as the ontogeny of shrubs in successive years, but as the growth of branches and leaves of canopies in a single growing season. In addition, the positive effects of canopy shading were proved to be more likely at intermediate light levels, and could be lost under deep shade (Holmgren et al., 2012). Thus it probably results in distinct effects of canopy shading among growth periods or shrub species with different canopy traits. It has been widely accepted that positive and negative interactions coexistent in the community, and their relative intensity determines the direction and magnitude of net plant-plant interactions (Callaway et al., 2002; Brooker et al., 2005; Maestre et al., 2009). Based on these evidences, we assume that the negative effect of light interception beneath $C$. mongolicum cannot outweigh positive effect from shrub canopies. By contrast, the costs of canopy shading by N. sphaerocarpa probably increase faster than its benefits as plant growth, causing the net shrub-annual interaction switches from positive to negative along the course during the growing season.

Although facilitations are very common under stressful conditions in arid and semi-arid lands, competition is also expected. For example, root competition from mature plants can reduce the survival of their understory plants (Good et al., 2014; Shiponeni et al., 2014), or leading to an overall neutral plant-plant interaction (Poulos et al., 2014). Yet at times root segregations may result in niche partitioning between shrubs and grasses (Soliveres et al., 2010), which enables the growth of a dense stand of annuals under shrubs. Unlike most of shrubs (include C. mongolicum), N. sphaerocarpa always produces an abundant of shallow adventitious root due to repeated sand burial. Thus, we speculate that the stronger underground niche overlaps between $N$. sphaerocarpa and grasses may lead to a dominant competitive interaction at lately growth period. For testing this hypothesis, more investigations about root architecture of different species and in different growing period are needed.

Benefactors have been proved to be more important than beneficiaries in determining interaction outcomes (Gómez-Aparicio et al., 2004), whereas our results demonstrated that the understory plants still showed species-specific responses to shrub canopies. By different responses to canopy shading and available water, these understory annuals can be classified into two categories. B. dasyphylla and S. collina seem more likely to be inhibited by deep shading under $N$. sphaerocarpa in lately growing season, but may bene- 
fit a lot from higher soil moisture or lower soil temperature with moderate shading. By contrast, $H$. arachnoideus and C. virgata are not subject to deep shading, while benefit less from water increases beneath shrub canopies. Obviously, these two categories of desert annuals show differences in adaptive strategies, and probably indicate a trade-off between drought tolerance and competitive ability. $B$. dasyphylla and S. collina are drought intolerant and competitively dominant, while $H$. arachnoideus and $C$. virgata are drought tolerant and competitively inferior. This finding agrees with a recent study in salinity-driven stressful habitats, which suggested that the contrasting stress tolerance and competitive ability of beneficiaries underlie their facilitative and competitive interactions with benefactors (He et al., 2012). It was also proposed that facilitation was more likely within certain range of environmental conditions, fading under deep shade, especially for drought tolerant species (Holmgren et al., 2012). This contrast in adaptive strategies will result in species-specific mechanisms and responses to neighbors, allowing us to predict plant-plant interactions in communities (Callaway et al., 2005) and zonation patterns along stress gradients (Pennings et al., 2005).

We conclude that the balance between competitive and facilitative effects in shrub-annual interactions is not only governed by the severity of stress but also determined by plant traits, such as canopy structure of shrubs and functional traits of their understory annuals. Although SGH has been proved repeatedly across widely species and ecosystems, plant-plant interactions could be different when studies involve temporal effects. Our results provide some implications for understanding stress-interaction pattern, suggesting the importance of species-specific traits. Meanwhile, we are aware that functional traits, such as drought tolerance and competitive ability, could determine outcomes of species interactions, and further experiments are required to explore facilitations across species with contrasting adaptive strategies in arid climate. Response patterns found here can improve our ability to understand biotic interactions for community composition and diversity, and predict vegetation responses to environmental change in arid desert.

\section{Acknowledgements}

This work was financial supported by the National Basic Research Program of China (2013CB429903) and the National Natural Science Foundation of China (41301603).

\section{References}

Armas C, Ordiales R, Pugnaire F I. 2004. Measuring plant interactions: a new comparative index. Ecology, 85(10): 2682-2686.

Armas C, Pugnaire F I. 2005. Plant interactions govern population dynamics in a semi-arid plant community. Journal of Ecology, 93(5): 978-989.

Armas C, Pugnaire F I. 2009. Ontogenetic shifts in interactions of two dominant shrub species in a semi-arid coastal sand dune system. Journal of Vegetation Science, 20(3): 535-546.

Armas C, Kim J, Bleby T, et al. 2012. The effect of hydraulic lift on organic matter decomposition, soil nitrogen cycling, and nitrogen acquisition by a grass species. Oecologia, 168(1): 11-22.

Bertness M, Ewanchuk P. 2002. Latitudinal and climate-driven variation in the strength and nature of biological interactions in New England salt marshes. Oecologia, 132(3): 392-401.

Brooker R W, Kikvidze Z, Pugnaire F I, et al. 2005. The importance of importance. Oikos, 109(1): 63-70.

Brooker R W, Maestre F T, Callaway R M, et al. 2008. Facilitation in plant communities: the past, the present, and the future. Journal of Ecology, 96(1): 18-34.

Bruno J F, Stachowicz J J, Bertness M D. 2003. Inclusion of facilitation into ecological theory. Trends in Ecology and Evolution, 18(3): $119-125$

Bulleri F, Xiao S, Maggi E, et al. 2014. Intensity and temporal variability as components of stress gradients: implications for the balance between competition and facilitation. Oikos, 123(1): 47-55.

Callaway R, Brooker R W, Choler P, et al. 2002. Positive interactions among alpine plants increase with stress. Nature, 417(6891): 844-848.

Callaway R, Kikodze D, Chiboshvili M, et al. 2005. Unpalatable plants protect neighbors from grazing and increase plant community diversity. Ecology, 86(7): 1856-1862.

Callaway R. 2007. Positive Interactions and Interdependence in Plant Communities. Netherlands: Springer, 179-254.

Cavieres L, Badano E, Sierra-Almeida A, et al. 2006. Positive interactions between alpine plant species and the nurse cushion plant Laretia acaulis do not increase with elevation in the Andes of central Chile. New Phytologist, 169(1): 59-69.

Choler P, Michalet R, Callaway R. 2001. Facilitation and competition on gradients in alpine plant communities. Ecology, 82(12): 3295-3308.

Chu C J, Weiner J, Maestre F T, et al. 2009. Positive interactions can increase size inequality in plant populations. Journal of Ecology, 97(6): 1401-1407.

Dohn J, Dembélé F, Karembé M, et al. 2013. Tree effects on grass growth in savannas: competition, facilitation and the stress-gradient hypothesis. Journal of Ecology, 101(1): 202-209.

Good M K, Clarke P J, Price J N, et al. 2014. Seasonality and facilitation drive tree establishment in a semi-arid floodplain savanna. Oecologia, 
175(1): 261-271.

Gómez-Aparicio L, Zamora R, Gómez J M, et al. 2004. Applying plant facilitation to forest restoration: A meta-analysis of the use of shrubs as nurse plants. Ecological Applications, 14(4): 1128-1138.

Hautier Y, Niklaus P A, Hector A. 2009. Competition for light causes plant biodiversity loss after eutrophication. Science, 324(5927): 636-638.

He Q, Cui B S, An Y. 2011. The importance of facilitation in the zonation of shrubs along a coastal salinity gradient. Journal of Vegetation Science, 22(5): 828-836.

He Q, Cui B S, Bertness M D, et al. 2012. Testing the importance of plant strategies on facilitation using congeners in a coastal community. Ecology, 93(9): 2023-2029.

He Q, Bertness M D. 2014. Extreme stresses, niches and positive species interactions along stress gradients. Ecology, 95(6):1437-1443.

Holmgren M, Gómez-Aparicio L, Quero J, et al. 2012. Non-linear effects of drought under shade: reconciling physiological and ecological models in plant communities. Oecologia, 169(2): 293-305.

Holzapfel C, Mahall B E. 1999. Bidirectional facilitation and interference between shrubs and annuals in the Mojave Desert. Ecology, 80(5): 1747-1761.

Kidron G J, Gutschick V P. 2013. Soil moisture correlates with shrub-grass association in the Chihuahuan Desert. Catena, 107: 71-79.

Kikvidze Z, KhetsurianiL, Kikodze D, et al. 2006. Seasonal shifts in competition and facilitation in subalpine plant communities of the central Caucasus. Journal of Vegetation Science, 17(1): 77-82.

Kikvidze Z, Callaway R M. 2009. Ecological facilitation may drive major evolutionary transitions. BioScience, 59(5): 399-404.

Kikvidze Z, Suzuki M, Brooker R. 2011. Importance versus intensity of ecological effects: why context matters. Trends in Ecology and Evolution, 26(8): 383-388.

Koyama A, Tsuyuzaki S. 2013. Facilitation by tussock-forming species on seedling establishment collapses in an extreme drought year in a post-mined Sphagnum peatland. Journal of Vegetation Science, 24(3): 473-483.

Li J, Zhao C Y, Song Y J, et al. 2010. Spatial patterns of desert annuals in relation to shrub effects on soil moisture. Journal of Vegetation Science, 21(2): 221-232.

Ludwig F, Dawson T E, Prins H H T, et al. 2004. Below-ground competition between trees and grasses may overwhelm the facilitative effects of hydraulic lift. Ecology Letters, 7(8): 623-631.

Maestre F T, Bautista S, Cortina J. 2003. Positive, negative, and net effects in grass ${ }^{-}$shrub interactions in Mediterranean semiarid grasslands. Ecology, 84(12): 3186-3197.

Maestre F T, Cortina J. 2004. Do positive interactions increase with abiotic stress? A test from a semi-arid steppe. Proceedings of the Royal Society of London. Series B: Biological Sciences, 271(Suppl. 5): S331-S333.

Maestre F T, Escolar C, Martínez I, et al. 2008. Are soil lichen communities structured by biotic interactions? A null model analysis. Journal of Vegetation Science, 19(2): 261-266.

Maestre F T, Callaway R M, Valladares F, et al. 2009. Refining the stress-gradient hypothesis for competition and facilitation in plant communities. Journal of Ecology, 97(2): 199-205.

Mauchamp A, Janeau J L. 1993. Water funnelling by the crown of Flourensia cernua, a Chihuahuan Desert shrub. Journal of Arid Environments, 25(3): 299-306.

Michalet R. 2006. Is facilitation in arid environments the result of direct or complex interactions? New Phytologist, 169(1): 3-6.

Miriti M N. 2006. Ontogenetic shift from facilitation to competition in a desert shrub. Journal of Ecology, 94(5): 973-979.

Moro M J, Pugnaire F I, Haase P, et al. 1997. Effect of the canopy of Retama sphaerocarpa on its understorey in a semiarid environment. Functional Ecology, 11(4): 425-431.

Pennings S C, Grant M B, Bertness M D. 2005. Plant zonation in low-latitude salt marshes: disentangling the roles of flooding, salinity and competition. Journal of Ecology, 93(1): 159-167.

Poulos J M, Rayburn A P, Schupp E W. 2014. Simultaneous, independent, and additive effects of shrub facilitation and understory competition on the survival of a native forb (Penstemon palmeri). Plant Ecology, 215(4): 517-426.

Reisman-Berman O. 2007. Age-related change in canopy traits shifts conspecific facilitation to interference in a semi-arid shrubland. Ecography, 30(4): 459-470.

Roux P, McGeoch M. 2010. Interaction intensity and importance along two stress gradients: adding shape to the stress-gradient hypothesis. Oecologia, 162(3): 733-745.

Schramm J, Ehrenfeld J. 2010. Leaf litter and understory canopy shade limit the establishment, growth and reproduction of Microstegium vimineum. Biological Invasions, 12(9): 3195-3204.

Shiponeni N N, Carrick P J, Allsopp N, et al. 2014. Effects of root competition and soils on seedling establishment at the ecotone between an arid grassland and succulent shrubland in South Africa. Journal of Vegetation Science, 25(2): 402-410.

Soliveres S, DeSoto L, Maestre F T, et al. 2010. Spatio-temporal heterogeneity in abiotic factors modulate multiple ontogenetic shifts between competition and facilitation. Perspectives in Plant Ecology and Evolution Systematics, 12(3): 227-234.

Sthultz C M, Gehring C A, Whitham T G. 2007. Shifts from competition to facilitation between a foundation tree and a pioneer shrub across spatial and temporal scales in a semiarid woodland. New Phytologist, 173(1): 135-145.

Valladares F, Niinemets Ü. 2008. Shade tolerance, a key plant feature of complex nature and consequences. Annual Review of Ecology, Evolution, and Systematics, 39(1): 237-257.

Veblen K E. 2008. Season- and herbivore-dependent competition and facilitation in a semiarid savanna. Ecology, 89(6): 1532-1540.

Weedon J T, Facelli J M. 2008. Desert shrubs have negative or neutral effects on annuals at two levels of water availability in arid lands of South Australia. Journal of Ecology, 96(6): 1230-1237.

Zhao W Z, Hu G L, Zhang Z H, et al. 2008. Shielding effect of oasis-protection systems composed of various forms of wind break on sand fixation in an arid region: A case study in the Hexi Corridor, northwest China. Ecological Engineering, 33(2): 119-125.

Zhao W Z, Liu B. 2010. The response of sap flow in shrubs to rainfall pulses in the desert region of China. Agricultural and Forest Meteorology, 150(9): 1297-1306. 